Zhelezov D. M., Kossey T. V., Zarzhitskaya N. A. Features of myometrium remodeling after surgical inteventions on the uterus. Journal of Education, Health and Sport. 2020;10(2):204-211. eISSN 2391-8306. DOI http://dx.doi.org/10.12775/JEHS.2020.10.02.025 https://apcz.umk.pl/czasopisma/index.php/JEHS/article/view/JEHS.2020.10.02.025

https://zenodo.org/record/3733425

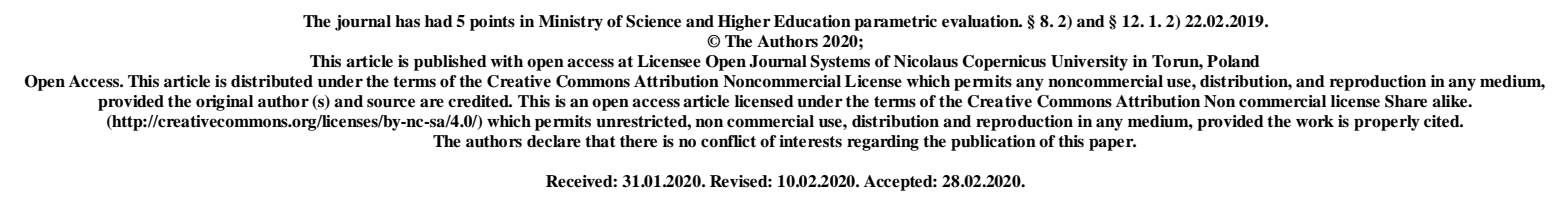

UDC 618.3-06

\title{
FEATURES OF MYOMETRIUM REMODELING AFTER SURGICAL INTEVENTIONS ON THE UTERUS
}

\author{
D. M. Zhelezov, T. V. Kossey, N. A. Zarzhitskaya
}

\section{Odessa National Medical University, Odessa}

\begin{abstract}
Introduction. Recently, the attention of researchers has again attracted the problem of pregnancy in the presence of scar on the uterus.

The aim of the study is to evaluate the processes of myometrium remodeling in women with uterine scar using non-invasive ultrasonic monitoring. It is shown that the frequency of relative failure of yellowing in the uterus does not exceed $2.7 \%$ of the total number of women examined. The ratio of the thickness of the residual in the plane of the yellow and normal endometrium indicates complete remodeling and is in women after KP, this index was $0.96 \pm 0.08$, and after KME - $0.94 \pm 0.06$ ( $p>0.05)$. The difference in maximum systolic velocity of arterial blood flow in patients after CR $(38.8 \pm 1.2 \mathrm{~cm} / \mathrm{s})$ and after CME $(34.2 \pm 1.4 \mathrm{~cm} / \mathrm{sec}, \mathrm{p}<0.05)$ can be explained by differences in localization cuts during these surgical interventions. The expediency of using both linear and dopplerometric methods of ultrasound examination in evaluating the ability of rumen on the uterus and myometrium remodeling processes is discussed.
\end{abstract}

Keywords: scar on the uterus; remodeling; myometrium; diagnosis 
Introduction. Recently, the problem of pregnancy management in the presence and scar on the uterus $[1,2,5,18]$ has again attracted the attention of researchers. The reasons for surgical interventions on the uterus are diverse benign conditions and various cancers of the uterus and cervix uteri $[2,3,7]$. Even more often, scar on the uterus is the result of surgical delivery after a caesarean section (in the lower uterine segment, a corporal scar on the uterus), after pregravid conservative myomectomy, myomectomy during pregnancy (without opening the uterine cavity, with opening of the uterine cavity). Occasionally, uterine perforation is a consequence of uterine perforation with intrauterine interventions such as abortions, hysteroscopy, and other traumatic complications. Also described are scars on the uterus after ectopic pregnancy (in the interstitial section of the fallopian tube, at the junction of the vestibular horn of the uterus with the main uterine cavity, in the cervix after removal of the cervical pregnancy). After all, scar on the uterus could be formed after reconstructive plastic surgery (Strassman metroplasty, removal of the vestigial horn of the uterus, etc.) [13].

Today cesarean section (CS) is the most widely used in obstetrical practice surgery, performed as planned and urgent order. According to world statistics, the incidence of CS in different countries varies significantly: from 15-20\% in the Benelux and Scandinavia countries, to $56.0 \%$ in public health facilities and about $80.0 \%$ in private hospitals in Brazil. High frequency of CS is also recorded in Latin America, Egypt and China [11, 14]. This high incidence of operative delivery is connected with complicated course of the pregnancy and childbirth, the presence of extra genital diseases, pathological conditions of the myometrium, etc. $[5,14]$. It should be noted that the risk of complications after CS remains quite high. Therefore, the presence of a scar on the uterus is not an absolute contraindication to childbirth per via naturales. In recent years, ukrainian obstetricians are more likely to drive conservative labor by the CS, but, unfortunately, are often faced with a serious problem of scar insufficiency $[1,3,5,7,18]$ that could be due to postpartum endometritis, inadequate usage of electrosurgical energy with formation of coagulatory necrosis and formation of gross connective tissue scar. Some obstetric complications and extragenital diseases (severe forms of preeclampsia, presentation and premature detachment of the normally located placenta, obesity, anemia, chronic infections) lead to the development of secondary immunodeficiency, where incomplete repair of the dissected uterine wall could occur. The process of scar reparation on the uterus depend on a number of factors: medical technologies used in surgical intervention, the choice of suture material, the amount of blood loss and other aspects of surgeons training level [18]. 
Another problem which is commonly encountered by the obstetrician is the scar on the uterus after conservative myomectomy $(\mathrm{CME})$. Given the increase in the incidence of uterine fibroids in the female population (up to $77 \%$ in some contingents), the incidence of both laparotomy and laparoscopical myomectomy is increasing [4, 15].

The formation of inferior scar on the uterus is not a common but dangerous consequence of surgery on the uterus, which can cause complications in subsequent pregnancies. These complications may include: pregnancy attached to the uterus; placental enlargement; diastasis or rupture of the scar. Unfortunately, there is still uncertainty about the factors that lead to the formation of a defective scar [5].

Diagnosis and monitoring capacity of the scar on the uterus is carried out by using different imaging techniques [10]. The ultrasonographic method is now considered as «golden standard». Over the past 20 years, ultrasound markers of partial or total disability uterine scar $[8,12,16,17]$ were formulated. But still there is no clear understanding of remodeling process of myometrium in isthmical area.

Accumulated data about the morphology of uterine scar insolve distinguish the following criteria: 1) foci of connective tissue disorganization in the form of mucoid swelling, fibrinoid swelling and fibrinoid necrosis; 2) leyomyocytes necrosis, fromed in scar tissue and located on the borders with the scar, 3) intramural hematoma and multiple petechial hemorrhages, 4) inflammatory infiltration of lymphohistiocytosical nature with significant content of polimorfo-nuclear leukocytes, 5) signs of neoangiogenesis in [2, 3].

It is believed that after surgery, the reparatory processes in the myometrium normally flow due to the regeneration of smooth muscle cells (so-called morphological restitution). In case of tissue repair violatin by the mechanism of substitution reparative processes with disorganization of both collagen fibrils and intercellular matrix, expressed inflammatory reaction, impaired angiogenesis [3] are observed. Sometimes incomplete second repair scar tissue forming coarse septums could spread to surrounding layers of the myometrium.

The aim of the study is to evaluate the processes of myometrial remodeling in women with scarring on the uterus using non-invasive ultrasound monitoring.

\section{Material and methods}

Research done at the Odessa Regional Perinatal center during the 2016-2018. The total number of clinical cases included in the study were 113 women delivered promptly according to the order № 977 from 27.12.2011 Ministry of Health [14] and 289 women who performed conservative myomectomy. The average age of the women surveyed was $32.1 \pm 0.9$ years. 
The obstetric and general medical history, the term from the moment of performing the CS, the peculiarities of realization of the childbearing function were analyzed.

All patients held transvaginal ultrasound using a scanner expert class Accuvix V20 Prestige (Samsung Medison, Korea). All studies were performed regardless of the phase of the menstrual cycle, with the empty bladder in a supine position.

The scar was measured in transverse and sagittal planes, indicating three dimensions (length, width and depth). In all cases, the measured distance from the inner orifice to the outer serous membrane of the uterus (UH), thickness of the myometrium in the area of the scar (SM), the thickness of the scar on the outside serosa (SS). In the sagittal plane, the depth of the scar (D) and its width (W) in the basal part were measured. The length of the scar (L) was measured in the transverse plane. The ratio of the thickness of the residual myometrium in the area of the scar to the thickness of the normal myometrium (SM/NM) was additionally calculated $[8,12]$.

Also evaluated the position of the scar, presence and absence of deformation, "recesses", locations of retraction of serous membrane and uterine cavity, including liquids; thickness of the myometrium in the area in the region of the lower uterine segment, the presence of local thinning areas; presence or absence of connective tissue inclusions; adequacy of blood flow in the area of the scar; condition of cystic -uterine fold, Douglas space, parametrical area.

US- hysteroscopy was performed in 65 women. Assessed the color of the scar, the presence of deformities. Extra carried doplerometrical investigation of blood flow in the uterine artery. Transabdominal and transvaginal sensors with a frequency of $3.5 \mathrm{MHz}$ and 7 $\mathrm{MHz}$ were used. Uterine arteries were identified in sagittal crossing at the level of the internal os, moving transvaginal probe to the sides of the uterus. Further research conducted with registration of intrauterine blood flow to different segments of the uterine vessels, with the definition of the degree of vascularization and evenly spine intrauterine perfusion.

Statistical analysis was performed using Statistica 13.0 software (Dell Inc., USA) [9].

\section{Results}

In the analysis of obstetrical history in the examined patients, it was determined that all had passed more than 2 years since the performing of the CS. Some patients had a history of more than one episode of operative delivery (Table 1). 
The peculiarity and a history of women after CK

\begin{tabular}{|c|c|c|c|}
\hline \multirow{2}{*}{\multicolumn{2}{|c|}{ Sign }} & \multicolumn{2}{|c|}{ Frequency of signs } \\
\hline & & Abs. & $\%$ \\
\hline \multirow{3}{*}{$\begin{array}{l}\text { The time that has } \\
\text { elapsed since the CS }\end{array}$} & $2-3$ years & 91 & 80.5 \\
\hline & $3-5$ years & 28 & 24,8 \\
\hline & More than 5 years & 4 & 3.5 \\
\hline \multirow{4}{*}{$\begin{array}{l}\text { Number of } \\
\text { pregnancies }\end{array}$} & 1 & 74 & 65,5 \\
\hline & 2 & 29 & 25.7 \\
\hline & 3 & 7 & 6.2 \\
\hline & More than 3 & 3 & 2.7 \\
\hline \multirow{3}{*}{$\begin{array}{l}\text { Number of cases of } \\
\text { operative delivery }\end{array}$} & 1 & 77 & 68.1 \\
\hline & 2 & 30 & 26.5 \\
\hline & More than 2 & 6 & 5,3 \\
\hline
\end{tabular}

For patients who developed a scar on the uterus as a result of conservative myomectomy, most of them had laparotomy access (196 or 67.8\%), while others had laparoscopic surgery. The average term after the CME was $2.8 \pm 0.2$ years. Unlike women after $\mathrm{CS}$, in whom the incision has always been localized in the lower uterine segment, in patients with a scar on the uterus after CME, its localization corresponded to the primary localization of the removed myomatous node. Most commonly reported were fundal (35.6\%) and corporate $(50.2 \%)$ cuts.

In most patients, the scar was consolidated at the time of the examination.

11 women with signs of relative unable spine rub showed to be in the form of deformation of the outer contour of the uterus in the lower segment at the isthmical level, a sharp thinning myometrium, the existence of "recesses" from the uterine cavity, or as forming wide with connective tissue non-vascular scar (Pic. 1)

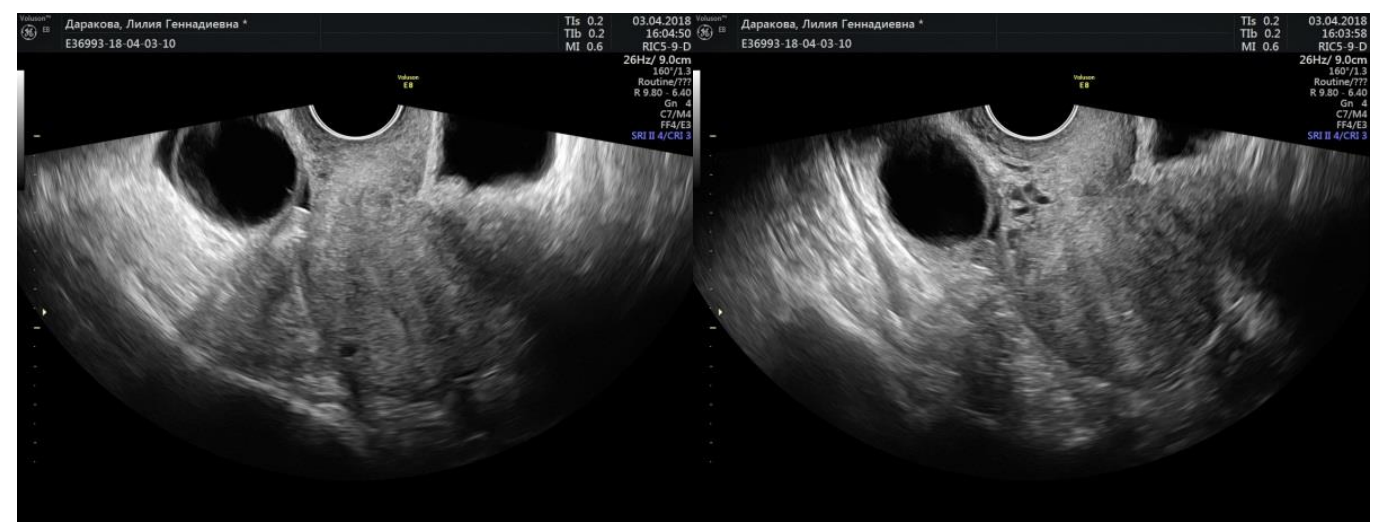

Pic. 1 Inability to scar on the uterus 
As for the geometry of the muscle fibers in the pericyclic region, it was not visually different from the intact sections. In the analysis of the ratio of the thickness of the residual and normal endometrium data were obtained, indicating its complete remodeling - in women after CS this figure was 0.96 \pm 0.08 , and after CME - 0.94 $\pm 0.06(\mathrm{p}>0.05)$

In ultrasound-guided hysteroscopy scar, typically, had a pink color, only $11(2.7 \%)$ cases were determined whitish inclusion and / or deformed scar that indicate its failure.

Interesting results were obtained regarding the features of uterine blood flow (Table 2). Thus, the resistance index (IR) in women after CS was $0.71 \pm 0.08$, in women after CME $0.74 \pm 0.07$, ie, these indicators were practically no different $(p>0.05)$.

Table 2

Doppler metastatic characteristics of uterine blood flow in patients with uterine scar

\begin{tabular}{|l|c|c|}
\hline \multicolumn{1}{|c|}{ Indicator } & Women after CR & Women after CME \\
\hline IR in the uterine arteries & $0.71 \pm 0.08$ & $0.74 \pm 0.07$ \\
\hline $\begin{array}{l}\text { MSV in uterine arteries, cm / } \\
\mathrm{s}\end{array}$ & $38.8 \pm 1.2 *$ & $34.2 \pm 1.4$ \\
\hline
\end{tabular}

Notes: * - differences between groups are statistically significant $(\mathrm{p}<0.05)$

But, maximum systolic arterial blood flow velocity in patients after CS was higher $(38.8 \pm 1,2 \mathrm{~cm} / \mathrm{s})$ than in women after CME $(34,2 \pm 1,4 \mathrm{~cm} / \mathrm{s}, \mathrm{p}<0,05)$. We explain this by the fact that the localization of the incisions at these surgical interventions was different - in the case of CS, the incision corresponds to the lower segment, whereas in CME the incision localization corresponds to the primary localization of myomatous nodes.

Overall, the analysis showed the feasibility of using both linear and Doppler ultrasound methods to evaluate the ability of the scar in the uterus and processes of myometrial remodeling.

\section{Conclusions:}

1. The incidence of relative scarring of the uterus does not exceed $2.7 \%$ of the total number of women examined

2. The ratio of the thickness of the residuals in the planes and the scar and the normal endometrium indicates complete remodeling and in women after CS this figure was $0.96 \pm 0.08$, and after CME $-0.94 \pm 0.06(\mathrm{p}>0.05)$

3. The difference in maximum systolic velocity of arterial blood flow in patients after CS $(38.8 \pm 1.2 \mathrm{~cm} / \mathrm{s})$ and after CME $(34.2 \pm 1.4 \mathrm{~cm} / \mathrm{s}, \mathrm{p}<0.05)$ may be explained by differences in localization of incisions during these surgical interventions. 


\section{Literature:}

1. Buyanova SN Unstable scar on the uterus after cesarean section: diagnosis, management tactics, reproductive prognosis /SN Buyanova, NV Puchkova// Russian Gazette of Obstetrician-Gynecologist. 2011. T. 11. № 4. P. 36-38.

2. Vakalyuk LM Scar on the uterus after caesarean section on clinical and morphofunctional analysis/ LM Vakalyuk// Health of a woman. - 2014. - № 3. - P. 91-93

3. Goncharuk NP Diagnosis of scar failure on the uterus after caesarean section (Literature review) / NP Goncharuk, NR Kovid// Women's Health. - 2016. - № 7. - P. 171173.

4. Kaminsky, VV Sonoelastography as a method of differential diagnosis of uterine leiomyoma/ VV Kaminsky, VV Dunaevskaya, MV Degtyaryuk. //Women's Health 2012 No. 7- P.63-65

5. Masalova Yu.K. The incomplete scar on the uterus after caesarean section: causes of formation, features of the course and management of pregnancy /Masalova Yu.K. //In the collection: New technologies in obstetrics, gynecology, perinatology and reproductive medicine Proceedings, program of the III International Congress. Ed. N. M. Pasman, M. Yu. Denisova. 2017, pp. 120-121.

6. Order of the Ministry of Health of Ukraine yiny №977 from 27.12.2011"On making changes to the order of the Ministry of Health of Ukraine from 12.15.20 03 roku N 582 "On approval of clinical protocols on obstetrical and gynecological care" https://zakon.rada.gov.ua/ rad / show / v0977282-11

7. Comparative analysis of outcomes of vaginal birth in patients with scarring on the uterus / OV Prokhorov, TA Oboskalova, KG Tikholaz, LA Vitebskaya// Ural Medical Journal. 2018. No. 5 (160). Pp. 12-16.

8. In ultrasound diagnostics of insolvency of the postoperative scar on the uterus/ Parkhatov SY, Nurmukhanova SN, Istekova AA, Sagitova RK// Bulletin of the Almaty State Institute for the Improvement of Doctors. 2012. No. 2 (18). Pp. 58-59.

9. Khalafyan A.L. Probability theory, mathematical statistics and data analysis: Fundamentals of theory and practice on the computer. STATISTICA. EXCEL. More than 150 examples of problem solving. URSC 2016320 p.

10. Anterior uterine wall: normal and abnormal CT and MRI findings after cesarean section Ali Devrim Karaosmanoğlu, Altan Güneş, Mustafa Nasuh Özmen, Deniz Akata Diagn Interv Radiol. 2018 May; 24 (3): 135-138. 
11. Burden, Prevalence, and Treatment of Uterine Fibroids: A Survey of US Women / Erica E. Marsh, Ayman Al-Hendy, Dale Kappus, Alex Galitsky, Elizabeth A. Stewart, Majid Kerolous J Womens Health (Larchmt) 2018 Nov 1; 27 (11): 1359-1367.

12. Callen's Ultrasonography in Obstetrics and Gynecology 6th Edition by Mary E Norton Elsevier; 6 edition 20161272 p.

13. Cao GS, Liu RQ, Liu YY, et al. Menstruation recovery in scar pregnancy patients undergoing UAE and curettage and its influencing factors. Medicine (Baltimore). 2018; 97 (11): e9584.

14. Mascarello KC, Horta BL, Silveira MF. Maternal complications and cesarean section without indication: systematic review and meta-analysis. Rev Saude Publica. 2017; 51: 105 .

15. Optimizing Research in Symptomatic Uterine Fibroids with Development of a Computable Phenotype for Use with Electronic Health Records Sarah R Hoffman, Anissa I VINES, Jacqueline R Halladay, Emily Pfaff, Lauren Schiff, Daniel Westreich, Aditi Sundaresan, La-Shell Johnson, Wanda K Nicholson Am J Obstet Gynecol. 2018 Jun; 218 (6): 610.e1-610.e7.

16. Prediction of uterine dehiscence using ultrasonographic parameters of cesarean section scar in nonpregnant uterus: a prospective observational study by Michal Pomorski, Tomasz Fuchs, Mariusz Zimmer BMC Pregnancy Childbirth. 2014; 14: 365.

17. Ultrasound evaluation of uterine scar after cesarean section Ejub Basic, Vesna Basic-Cetkovic, Hadzo Kozaric, Admir Rama Acta Inform Med. 2012 Sep; 20 (3): 149-153.

18. Why do niches develop in Caesarean uterine scars? Hypotheses on the aetiology of niche development AJMW Vervoort, LB Uittenbogaard, WJK Hehenkamp, HAM Brölmann, BWJ Mol, JAF Huirne Hum Reprod. 2015 Dec; 30 (12): 2695-2702. 